\title{
Analysis of Digital Elevation Model in Vaniyar River Basin, South India Using SRTM Data and GIS Techniques
}

\author{
${ }^{1}$ Ebenezer Sahayam Samuel. A and ${ }^{2}$ Dr. Sorna Chandra Devadass \\ School of Civil Engineering, Karunya University, \\ Coimbatore, Tamilnadu, India \\ Email: samuelebenezer@gmail.com
}

\begin{abstract}
In the present study, Digital Elevation Model (DEM) is used for the analysis of slope and aspects. The elevation features of a hilly terrain can be easily investigated using Shuttle Radar Topography Mission (SRTM) data and GIS methods. Hence, for the present study, SRTM data were downloaded and used. The study area covers an area of $982.25 \mathrm{~km}^{2}$ in Vaniyar river basin, South India. The result of elevation variation using DEM was analysed. Using this DEM output as input in ArcGIS to prepare the slope and aspect details of the study area were attempted. This output has immense application in proper planning and management of various natural resources and also very useful for the natural disaster management studies.
\end{abstract}

Keywords: GIS, SRTM, Slope, Aspect.

\section{Introduction}

A DEM is a representation of Earth surface with latitude, longitude and altitude, i.e. X; Y horizontal coordinates and height Z. DEMs play a significant tool for the extraction of three-dimensional models (Swaraj and Anji Reddy, 2013). Digital Elevation Model is a quantitative representation of terrain and is consequential for geological and hydrological applications (Gurugnanam et al., 2014). Generally, DEM of an area is studied using the elevation data, which in turn, is obtained through SRTM data (SubhashChavare, 2011, 
Gurugnanam et al., 2014).

The Vaniyar Sub-basin of Ponniyar River, Tamilnadu, has been selected for the present study. The study area, lies between the latitudes $11^{\circ} 46^{\prime} \mathrm{N}$ to $12^{\circ} 09^{\prime} 39^{\prime \prime} \mathrm{N}$ and longitudes $78^{\circ} 12^{\prime} 27^{\prime \prime} \mathrm{E}$ to $78^{\circ} 36^{\prime} 65^{\prime \prime} \mathrm{E}$ covering an area of $982.25 \mathrm{~km}^{2}$. Out of which plain land covers an area of $591.43 \mathrm{~km}^{2}$ (Fig. 1). The study area falls in Salem and Dharmapuri districts of Tamil Nadu. The base map was prepared from toposheets nos. 57L/4, 8, 58, I/1, and 5 of 1:50,000 Scale. The ephemeral stream Vaniyar has its source along the northern slopes of Shervorayan hills and originating at Kombur and takes a course along the northeast in the valley and emerges out as the main artery of Dharmapuri district with northeast gradient and small portion of catchment area falls in Salem district.

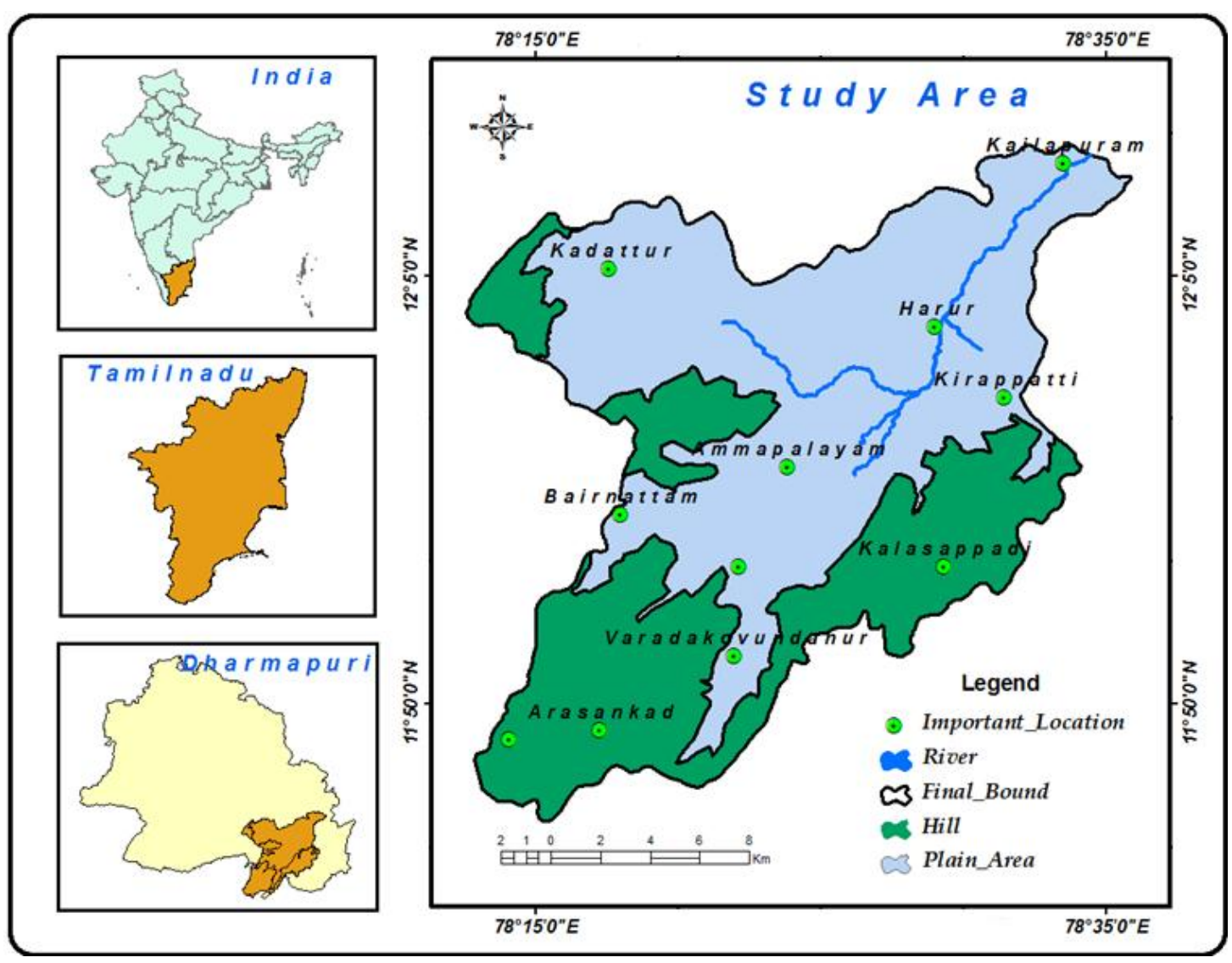

Fig.1. Location map of the study area.

\section{Methodology}

The elevation model resulting from Shuttle Radar Topography Mission (SRTM) data is used for DEM investigation. The SRTM data is provided by 
the international project of the U.S. National Geospatial Intelligence and NASA. The SRTM data has 30 meter resolution. The data is taken into ArcGIS software for preparation of digital elevation model (DEM), slope and aspect map ((Gonçalves, et al. (2008), Beijing Rabus, (2008), Rodriguez, et. al., (2006), Smith (2003) and Gurugnanam and Kalaivanan (2014)). For the analysis of the slope and aspect, the surface analysis tool and 3D analysis tool were used in ArcGIS software. SRTM data is taken from the GLCF website for free.

\section{Results and Discussion}

\section{Digital Elevation Model}

The digital elevation model is a three-dimensional digital representation of a terrain surface. It is generated using SRTM data. In the present study, the terrain elevation principles are used to prepare DEM. The elevation in the study differs between $300 \mathrm{~m}$ to $1600 \mathrm{~m}$. The DEM of the study shows that the southern part of the study has high elevation, lying between 1100 and $1600 \mathrm{~m}$ above mean sea level. The DEM map is shown in fig. 2.

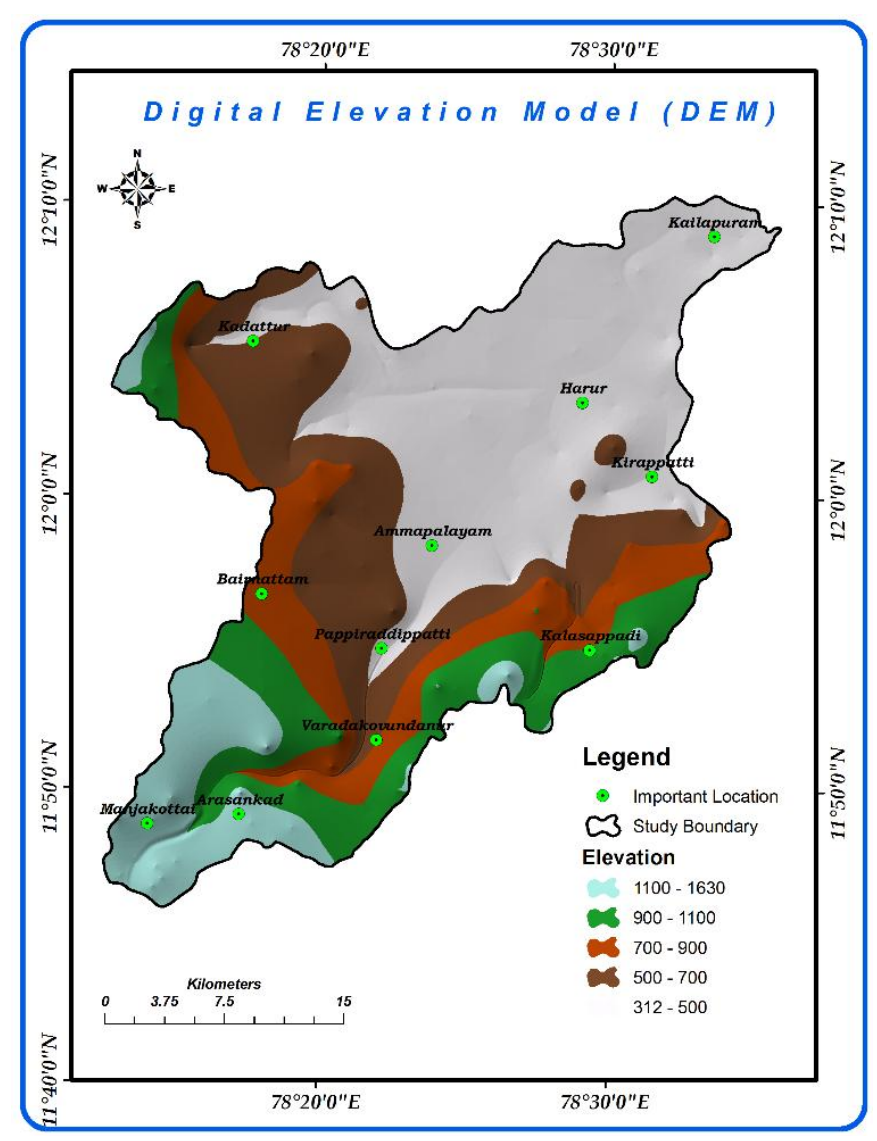

Fig. 2. DEM map of the study area. 


\section{Slope}

Slope is defined by plane refraction to a topographic surface, as showed by the DEM at a point. The DEM data continued given as in input for the preparation of Slope map. The slope of Vaniyar river basin is varied permitting to the direction. Very steep slope $\left(>35^{\circ}\right)$ covered small patches in southern and southeasterly parts study area. Moderate to steep slope $\left(15^{\circ}\right.$ $35^{\circ}$ ) are confined to the southwestern, southeastern and northwest part and a few patches in the northern part. Southwest, southeast and northwest part and a few patches covered northerly parts have moderate slope $\left(5^{\circ}-15^{\circ}\right)$. The Gentle slope $\left(0^{\circ}-5^{\circ}\right)$ areas are found to occupy more areas than any of the other slope classes. The slope map is given in (Fig.3).

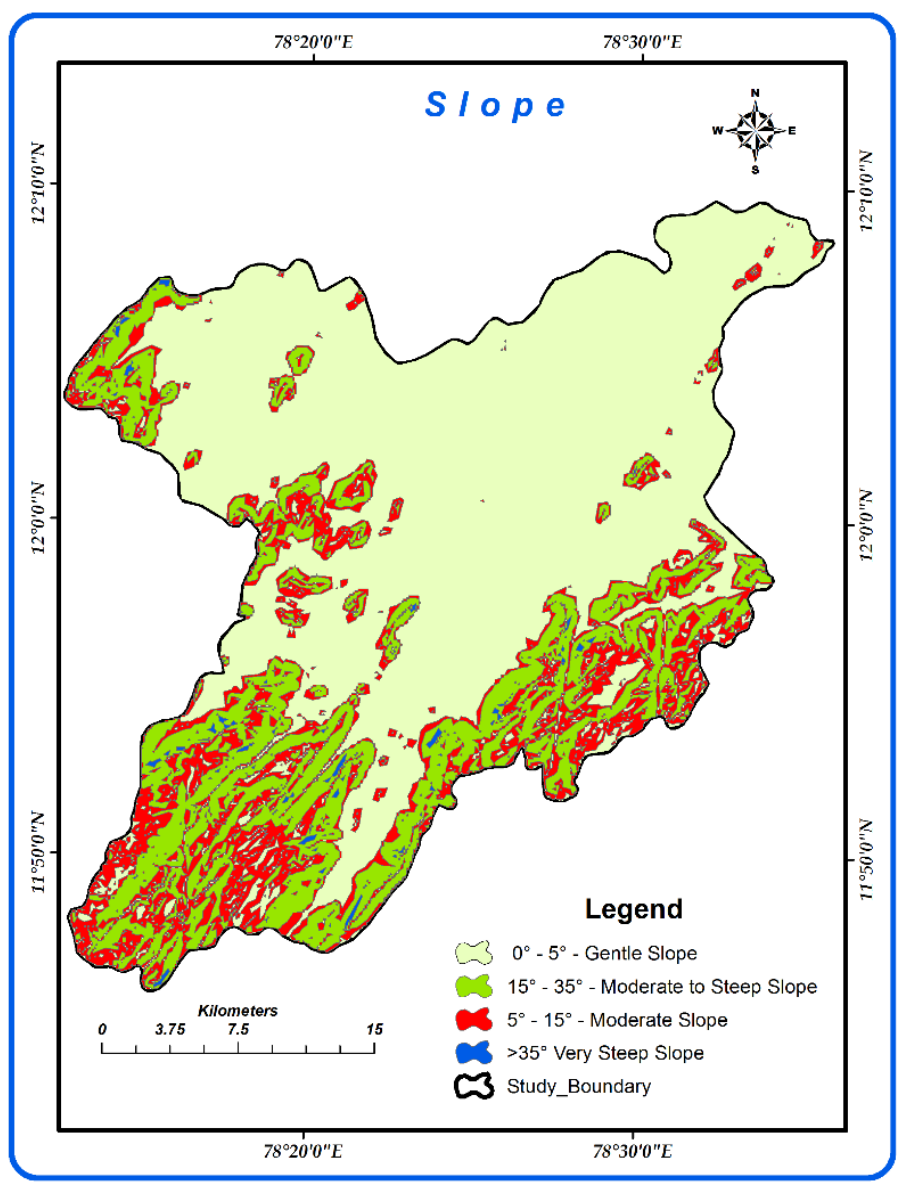

Fig.3. Slope map of the study area.

\section{Aspect}

Aspect is the directional measure of slope in degrees, and it ranges from the 0 degree at the North, moves the clock wise and end with 360 degrees at the 
North. Aspect can have a large impact on temperature. The aspect of a slope can make very important effects on its local climate. For example, because the sun's rays are in the west at the hottest time of day in the afternoon, in most cases, a westacing slope will be warmer than a sheltered east facing slope. In the study, DEM data and slope values are used to generate the Aspect map. This map is used to classify the slope direction. The map shows that most of the slopes in the study are westward, northward and northwest facing. Eastward dipping slopes occupy a least area. The Aspect map is given in (Fig.4).

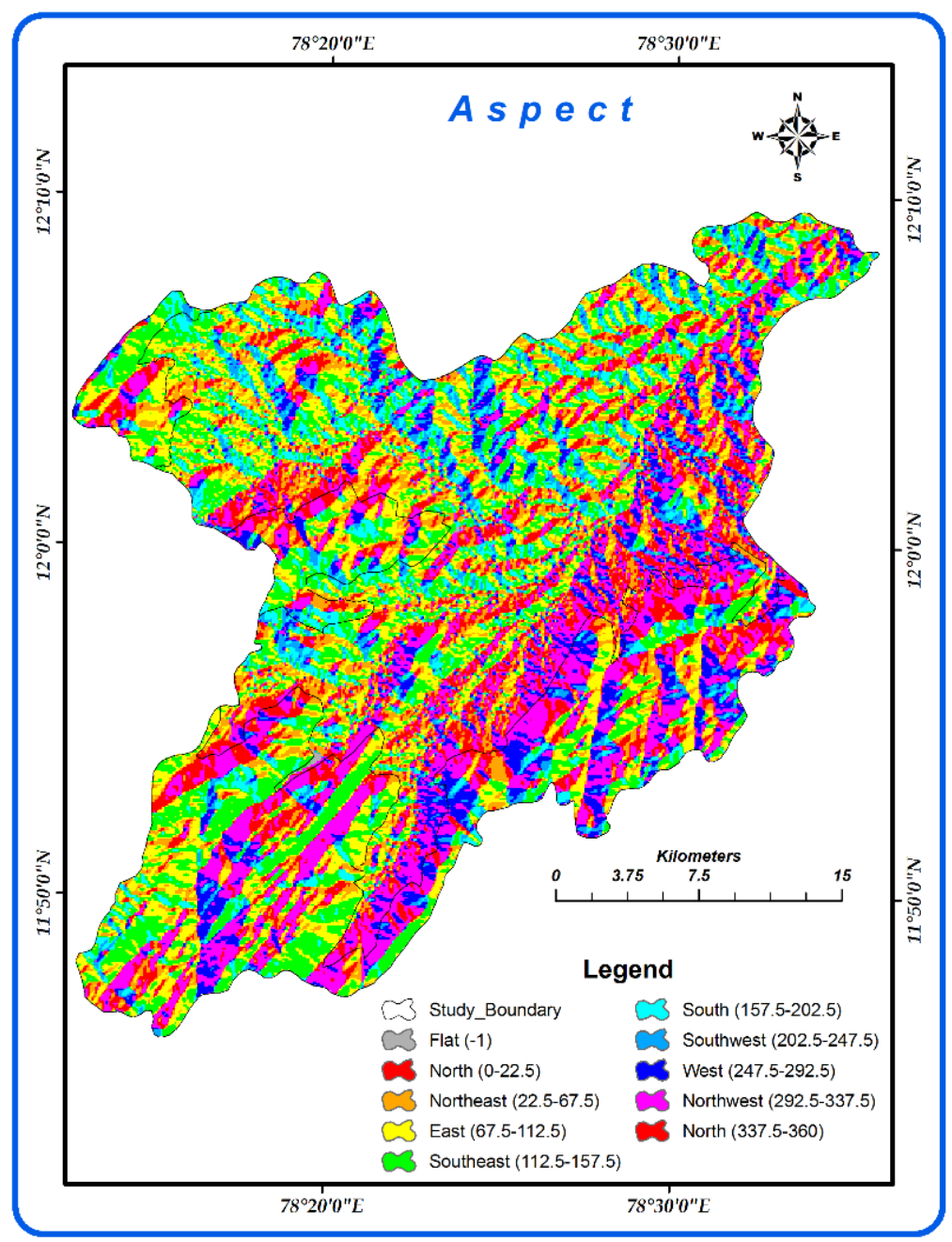

Fig.4. Aspect map of the area.

\section{Conclusion}

The present studyheighlighted the importance of DEM analysis and its applications from SRTM data and GIS Technology. The slope of Vaniyar river 
basin varied according to the location faces; very steep slope $\left(>35^{\circ}\right)$ covered small patches in southern and southeastern parts study area. Moderate to steep slope $\left(15^{\circ}-35^{\circ}\right)$ are confined to the southwest, southeast and northwest part and a few patches in the northern part. Southwest, southeastern and northwest part and a few patches covered northerly parts have moderate slope $\left(5^{\circ}-15^{\circ}\right)$. The Gentle slope $\left(0^{\circ}-5^{\circ}\right)$ areas are found to occupy more areas than any of the other slope classes. Relief in an area can be used to generate slope maps, DEM maps, Aspect maps, etc. These maps are very essential to delineate watersheds in a particular area. Digital elevation models (DEM) are efficient and effective methods used to deter-mine the features of drainage networks like size, length, and slope of drainage network and to determine the characteristics of basin and sub-basin.

\section{References}

[1] Beijing Rabus, B., M. Eineder, A. Roth, R., Bambler, (2008) The Shuttle Radar Topography Mission -a new class of digital elevation models acquired by space borne radar. ISPRS Journal of Photogrammetry and Remote Sensing. (57), p. 241-262.

[2] Gonçalves, J., Fernandes, (2005) Assessment of SRTM-3DEM in Portugal with topographic map data. Proceed-ings of the EAR Sel Workshop on 3D Remote Sensing. Porto, June, 2005. (CD-ROM).

[3] Gurugnanam. B and Kalaivanan. K, (2014) 3D Model Conception of Kolli Hill Using Geospatial Technologies, International Journal of Research (IJR) Vol-1, Issue-10, Pp.391-399.

[4] Gurugnanam. B and Kalaivanan. K, (2014) Village Level Detailed Relief Map Preparation Using SRTM Data and GIS in Kolli Hill, Tamil Nadu, India, Interna-tional Journal of Scientific Research, Volume: 3, Issue: 9, Pp.184-185.

[5] Mani, P. (1976). Report on the investigation for Bauxite in KolliMalai, Salem District, Tamil Nadu. Progress Re-port for the Field Season 1975 -1976. Geological Survey of India, Tamil Nadu Circle, Madras.

[6] Rodriguez, E., C.S. Morris, J.E. Belz, (2006) A global assessment of the SRTM performance, Photogramm. Eng. Rem. Sens., Vol. 72, p. 249-260.

[7] Smith, B., D. Sand well, (2003) Accuracy and Resolu-tion of shuttle radar topography mission data. Geo-physical Research Letters, Vol. 30, No. 9.IGP, 2007.

[8] SubhashChavare (2011). Analysis of Relief of Kolha-pur District using SRTM Data and GIS Techniques, In-ternational Referred Research Journal, ISSN: 0975-3486.RNI : RAJBIL 2009/30097,VOL-III, ISSUE 26, pp. 12-13. 
[9] Swaraj, J and Anji Reddy, M., (2013) Generation and Evaluation of Cartosat -1 DEM for Hyderabad city, Indian Journal of Applied Research, Volume: 3 Issue: 4. Pp.191-192.

[10] Gurugnanam. B, Kalaivanan. KandBairavi.S., (2014) Analysis of Digital Elevation Model of Kolli Hill, South India Using Shuttle Radar Topography Mission Data and GIS Techniques, International Journal of Remote Sensing \& Geoscience (IJRSG), Volume 3, Issue 6, Nov. Pp.41 43. 
